\title{
COMPARAÇÃO DE MÉTODOS PARA ESTIMAR A ACIDEZ POTENCIAL MEDIANTE DETERMINAÇÃO DO pH SMP EM ORGANOSSOLOS DA SERRA DO ESPINHAÇO MERIDIONAL ${ }^{(1)}$
}

\author{
Enilson de Barros Silva ${ }^{(2)}$, Alexandre Christófaro Silva ${ }^{(3)}$, Paulo Henrique \\ Grazziotti $^{(3)}$, Múcio Magno de Melo Farnezi ${ }^{(4)}$, Celmo Aparecido Ferreira ${ }^{(4)}$, \\ Hesmael Antonio Orlandi Costa ${ }^{(4)} \&$ Ingrid Horak ${ }^{(5)}$
}

\begin{abstract}
RESUMO
Apesar do potencial para uso agrícola e das características edáficas peculiares, poucos trabalhos são desenvolvidos para estimar a acidez potencial dos solos com elevado teor de matéria orgânica. O objetivo deste trabalho foi definir um modelo matemático que estime a acidez potencial $(\mathrm{H}+\mathrm{Al})$ a partir do $\mathrm{pH}$ SMP após determinação do pH do solo em água ou em solução de $\mathrm{CaCl}_{2} 10 \mathrm{mmol} \mathrm{L}^{-1}$, com leitura do pH na suspensão ou sobrenadante da solução SMP de equilíbrio, em determinada relação solo:tampão SMP, em Organossolos da Serra do Espinhaço Meridional (SdEM), Estado de Minas Gerais, situada entre $17^{\circ} 30^{\prime}$ a $20^{\circ} 30$ ' $\mathrm{S} \mathrm{e}$ $43^{\circ}$ a $44^{\circ} \mathrm{W}$. Foram utilizadas 22 amostras de Organossolos classificados como Organossolo Háplico sáprico térrico, Organossolo Háplico fíbrico típico e Organossolo Háplico hêmico típico da SdEM. A acidez potencial dos Organossolos da SdEM pode ser estimada satisfatoriamente por meio do pH SMP na relação solo:tampão SMP de 10:10 medido na suspensão solo-solução SMP associada à rotina de determinação do pH do solo em água. O C orgânico foi o atributo químico que mais influenciou a acidez potencial dos Organossolos da SdEM.
\end{abstract}

Termos de indexação: pH do solo, relação solo:tampão SMP, H + Al, carbono orgânico.

\footnotetext{
(1) Trabalho apresentado no XXXICBCS, Gramado (RS), de 05 a 10 de agosto de 2007. Recebido para publicação em outubro de 2007 e aprovado em julho de 2008.

(2) Professor Adjunto do Departamento de Agronomia, Universidade Federal dos Vales do Jequitinhonha e Mucuri - UFVJM. Rua da Glória 187, CEP 39100-000 Diamantina (MG). E-mail: ebsilva@ufvjm.edu.br

(3) Professor Adjunto do Departamento de Engenharia Florestal, UFVJM. E-mails: christo@jknet.com.br; grazziotti@yahoo.com.br

(4) Mestrando em Produção Vegetal, UFVJM. E-mails: muciomagno@yahoo.com.br; agrocel_1@yahoo.com.br; hesmaelorlandi@yahoo.com.br

(5) Mestranda em Solos e Nutrição de Plantas, Escola Superior de Agricultura "Luiz de Queiroz" - ESALQ. Caixa Postal 09, Av. Pádua Dias 11, CEP 13418-900 Piracicaba (SP). E-mail: ingridhorak@hotmail.com
} 


\title{
SUMMARY: COMPARISON OF ESTIMATION METHODS OF POTENTIAL ACIDITY BY DETERMINATION OF THE pH SMP IN ORGANOSOL OF THE REGION SERRA DO ESPINHAÇO MERIDIONAL, BRAZIL
}

\begin{abstract}
In spite of the agricultural use potential and the peculiar edaphic characteristics, few studies have been conducted to estimate the potential acidity of soils with high organic matter content. The objective of this study was to establish a mathematical model that could estimate the potential acidity $(H+A l)$ based on the $p H S M P$ after determination of the soil $\mathrm{pH}$ in water and in $\mathrm{CaCl}_{2} 10 \mathrm{mmol} \mathrm{L}^{-1}$ solution with reading of the $\mathrm{pH}$ in the suspension or supernatant of the equilibrium solution SMP in a certain soil: SMP buffer ratio for Organosols from the of Serra do Espinhaço Meridional (SdEM) region (between $17^{\circ} 30^{\prime}$ and $20^{\circ} 30^{\prime} \mathrm{S}$, and $43^{\circ}$ and $44^{\circ} \mathrm{W}$ ) in Minas Gerais State, Brazil. Twenty-two Organosol samples from the SdEM were used. The soils are classified as Terric Organosol Haplic sapric, Typical Organosol Haplic fibric and Typical Organosol Haplic hemic. The potential acidity of Organosols from SdEM can be estimated satisfactorily based on the pH SMP at a soil: SMP buffer ratio of 10:10 measured in the soil- SMP solution used in the routine soil water $\mathrm{pH}$ determination. Of the chemical attributes organic carbon was the one that most influenced the potential acidity of Organosol in SdEM.
\end{abstract}

Index terms: soil $p H$, soil:buffer $S M P$ ratio, $H+A l$, organic carbon.

\section{INTRODUÇÃO}

Os Organossolos são definidos como um grupo de solos constituídos por material orgânico, com teor de C orgânico maior ou igual a $80 \mathrm{~g} \mathrm{~kg}^{-1}$ na terra fina seca ao ar e horizonte hístico com espessura mínima de $40 \mathrm{~cm}$. Esse horizonte se estende em seção única a partir da superfície, ou tomada, cumulativamente, dentro de $80 \mathrm{~cm}$ de superfície do solo. Quando sobrejacente a um contato lítico ou material fragmentar, ele tem no mínimo $20 \mathrm{~cm}$ de espessura, ou máximo de $60 \mathrm{~cm}$ de espessura se $75 \%$ ou mais do material orgânico consiste de tecido vegetal facilmente identificável (Embrapa, 2006).

Esses solos são comumente denominados "Turfeiras" (Silva, 2005) e podem ocorrer em ambiente tropical de elevadas altitudes e clima atual ameno, como as da SdEM, que possuem idades superiores há 30.000 anos (Silva et al., 2004). Como as turfeiras são pouco estudadas, ainda é pequeno o número de informações a respeito de seu potencial para estudos de mudanças climáticas, de evolução das paisagens, de endemismos bióticos e da cronologia de deposições atmosféricas de metais pesados (Silva, 2005).

O elevado teor de matéria orgânica dos Organossolos confere a estes solos características químicas, físicas e biológicas peculiares, com efeitos contrastantes em relação aos solos minerais. Esses solos são quimicamente ácidos, com elevados teores de $\mathrm{Al}^{3+}$ trocável, características indesejáveis em solos minerais, mas geralmente têm menor impacto negativo para o desenvolvimento das plantas em solos orgânicos, devido à complexação do $\mathrm{Al}^{3+}$ pela matéria orgânica (Ebeling, 2006). Além disso, apresentam teores de $\mathrm{Ca}^{2+}$ e $\mathrm{Mg}^{2+}$ médios e os de $\mathrm{K}^{+}$baixos e, conseqüentemente saturação por bases baixa, aumentando com a profundidade. Sua capacidade de troca catiônica é elevada devido aos altos teores de matéria orgânica (Adriesse, 1988).

Aspecto importante ao manejo dos Organossolos refere-se ao conceito da acidez potencial e a determinação da fertilidade do solo, sendo esta acidez mais relacionada aos teores de ácidos orgânicos do que ao conteúdo de Al trocável (Lepsch et al., 1990). Embora tais solos apresentem características físicas e químicas próprias ou específicas, a recomendação de calagem utilizada tem sido baseada em solos minerais, com resultados nem sempre satisfatórios (Pereira et al., 2005).

O método SMP apresenta uma série de vantagens quando comparado à solução de acetato de Ca $0,5 \mathrm{~mol} \mathrm{~L}^{-1}, \mathrm{pH} 7,0$, que é o método mais comumente empregado na maioria dos laboratórios brasileiros para a determinação da acidez potencial (Silva et al., 2000). Dentre as principais limitações ao emprego do método do acetato de $\mathrm{Ca}$, destacam-se: a difícil visualização do ponto de viragem do indicador durante a titulação (Pereira et al., 2006); o custo de análise (Silva et al., 2000); e o tempo operacional para a realização da análise (Escostegy \& Bissani, 1999). Em função das limitações do método do acetato de $\mathrm{Ca}, \mathrm{a}$ acidez potencial vem sendo estimada no Brasil pelo método do pH SMP, que, segundo Sambatti et al. (2003) apresentam vantagens como simplicidade e rapidez do método associado ao baixo custo e eficiência. 
Embora o método do $\mathrm{pH}$ SMP tenha sido inicialmente desenvolvido para a determinação da necessidade de calagem (Raij et al., 1979) no Brasil, vários estudos foram realizados utilizando-se modelagem matemática de equações de regressão, que têm possibilitado estimar a acidez potencial a partir da determinação do $\mathrm{pH}$ do solo em equilíbrio com a solução SMP (Sousa et al., 1980; Freitas et al., 1986; Pereira et al., 1998; Sambatti et al., 2003; Silva et al., 2006). Entretanto, poucos desses estudos incluíram solos com elevados teores de matéria orgânica.

Portanto, o objetivo deste trabalho foi definir um modelo matemático que possibilite a estimação da acidez potencial $(\mathrm{H}+\mathrm{Al})$ a partir do $\mathrm{pH} \mathrm{SMP}$, após determinação do $\mathrm{pH}$ do solo em água ou em solução de $\mathrm{CaCl}_{2} 10 \mathrm{mmol} \mathrm{L}^{-1}$, com leitura do $\mathrm{pH}$ na suspensão ou sobrenadante do tampão SMP de equilíbrio em determinada relação solo:tampão SMP, para Organossolos da SdEM.

\section{MATERIAL E MÉTODOS}

Os Organossolos do estudo são de ocorrência da Serra do Espinhaço Meridional (SdEM), que engloba municípios de três macrorregiões do estado de Minas Gerais: Jequitinhonha, Rio Doce e Metalúrgica-
Campos das Vertentes. Esse geossistema corresponde a um conjunto maciço de relevos estruturais dobrados, quebrados e desnivelados por falhamentos, elaborados em quartzitos ortoquartzíticos e quartzitos conglomeráticos com intercalações lenticulares de filitos e xistos do Supergrupo Espinhaço (Brasil, 1997).

Foram selecionadas 22 amostras de Organossolos classificados como Organossolo Háplico sáprico térrico, Organossolo Háplico fíbrico típico e Organossolo Háplico hêmico típico da SdEM, de ocorrência entre as latitudes de $17^{\circ} 30^{\prime}$ a $20^{\circ} 30$ ' S e longitudes de $43^{\circ} \mathrm{a} 44^{\circ} \mathrm{W}$ e altitude média de $1.300 \mathrm{~m}$ no estado de Minas Gerais, classificados de acordo com Embrapa (2006) e caracterizado por Horák et al. (2007). Foram analisados nas amostras $\mathrm{pH}$ em água e $\mathrm{CaCl}_{2}$ $10 \mathrm{mmol} \mathrm{L}^{-1}, \mathrm{Al}^{3+}$ trocável conforme Embrapa (1997), C orgânico determinado em analisador FISONS - EA 1108 (Nelson \& Sommers, 1996), teor de argila pelo método da pipeta conforme Embrapa (1997) e acidez potencial $(\mathrm{H}+\mathrm{Al})$ pelo método do acetato de $\mathrm{Ca}$ 0,5 mol L-1, pH 7,0 conforme Silva (1999). A acidez potencial foi, posteriormente, correlacionada (correlação linear simples) com outros atributos químicos e físicos desses Organossolos da SdEM (Quadro 1).

Na determinação dos valores de acidez potencial foram utilizados $5,0 \mathrm{~cm}^{3}$ de terra fina seca ao ar (TFSA) com $75 \mathrm{~mL}$ de solução de acetato de $\mathrm{Ca}$

Quadro 1. Classificação dos solos selecionados e discriminação de alguns de seus atributos químicos e físicos (pH do solo, alumínio trocável $\left(\mathrm{Al}^{3+}\right)$, acidez potencial $(\mathrm{H}+\mathrm{Al})$, carbono orgânico (CO) e argila) da Serra do Espinhaço Meridional, Minas Gerais

\begin{tabular}{|c|c|c|c|c|c|c|}
\hline \multirow[t]{2}{*}{ Classificação do solo ${ }^{(1)}$} & \multicolumn{2}{|c|}{ pH do solo } & \multirow[t]{2}{*}{$\mathrm{Al}^{3+}$} & \multirow[t]{2}{*}{$\mathbf{H}+\mathbf{A l}$} & \multirow[t]{2}{*}{$\mathrm{CO}$} & \multirow[t]{2}{*}{ Argila } \\
\hline & Água & $\mathrm{CaCl}_{2}$ & & & & \\
\hline & & & $\mathrm{cmol}_{\mathrm{c}} \mathrm{dm}^{-3}$ & & $\mathrm{~g} \mathrm{~kg}^{-1}$ & \\
\hline \multicolumn{7}{|l|}{ Organossolo Háplico sáprico terriço } \\
\hline Amostra 01 & 4,3 & 3,7 & 0,5 & 10,2 & 160 & 6,5 \\
\hline Amostra 02 & 4,4 & 3,7 & 1,7 & 12,4 & 180 & 0,4 \\
\hline Amostra 03 & 4,5 & 4,1 & 1,2 & 8,1 & 130 & 4,4 \\
\hline Amostra 04 & 4,4 & 3,9 & 1,2 & 8,3 & 130 & 203,6 \\
\hline Amostra 05 & 4,7 & 4,0 & 1,0 & 7,1 & 80 & 6,4 \\
\hline Amostra 06 & 4,5 & 3,9 & 0,7 & 5,0 & 130 & 2,4 \\
\hline Amostra 07 & 4,7 & 4,0 & 1,4 & 11,5 & 140 & 4,5 \\
\hline \multicolumn{7}{|l|}{ Organossolo Háplico fíbrico típico } \\
\hline Amostra 01 & 2,9 & 2,7 & 1,2 & 67,2 & 493 & 2,8 \\
\hline Amostra 02 & 3,1 & 2,7 & 2,7 & 117,2 & 502 & 4,5 \\
\hline Amostra 03 & 3,0 & 2,8 & 3,4 & 117,2 & 489 & 11,6 \\
\hline Amostra 04 & 3,0 & 2,8 & 3,1 & 75,1 & 468 & 2,9 \\
\hline Amostra 05 & 2,8 & 2,7 & 6,0 & 146,4 & 492 & 2,8 \\
\hline Amostra 06 & 3,3 & 2,7 & 8,9 & 132,6 & 410 & 10,8 \\
\hline \multicolumn{7}{|l|}{ Organossolo Háplico hêmico típico } \\
\hline Amostra 01 & 4,4 & 3,8 & 1,8 & 15,3 & 239 & 4,7 \\
\hline Amostra 02 & 4,5 & 3,8 & 2,3 & 20,6 & 292 & 4,7 \\
\hline Amostra 03 & 4,8 & 3,6 & 4,8 & 28,0 & 372 & 1,5 \\
\hline Amostra 04 & 4,3 & 3,7 & 5,5 & 59,7 & 449 & 0,5 \\
\hline Amostra 05 & 4,5 & 3,8 & 6,7 & 38,3 & 461 & 0,5 \\
\hline Amostra 06 & 4,3 & 3,9 & 5,7 & 22,8 & 471 & 104,4 \\
\hline Amostra 07 & 4,3 & 3,9 & 6,3 & 48,9 & 462 & 0,4 \\
\hline Amostra 08 & 4,3 & 4,1 & 5,5 & 46,1 & 478 & 4,6 \\
\hline Amostra 09 & 3,7 & 3,6 & 11,0 & 62,2 & 488 & 0,4 \\
\hline
\end{tabular}

(1) Embrapa (2006). pH do solo: relação solo:água ou $\mathrm{CaCl}_{2} 1: 2,5 ; \mathrm{Al}^{3+}$ : extrator $\mathrm{KCl} 1$ mol L $\mathrm{L}^{-1}$ e dosagem titulométrica ácido-base; $\mathrm{H}+\mathrm{Al}$ : extrator acetato de cálcio $0,5 \mathrm{~mol} \mathrm{~L}^{-1}$ a pH 7,0 e dosagem titulométrica ácido-base; CO: carbono orgânico determinado em analisador FISONS (EA 1108) e Argila: método da pipeta (Embrapa, 1997). 
$\left(\mathrm{Ca}\left(\mathrm{CH}_{3} \mathrm{COO}\right)_{2} \cdot \mathrm{H}_{2} \mathrm{O}\right) 500 \mathrm{mmol} \mathrm{pH}$ 7,0, em erlenmeyer de $125 \mathrm{~mL}$. Após agitação por $15 \mathrm{~min}$ a $23 \mathrm{rad} \mathrm{s}^{-1} \mathrm{e}$ repouso de $16 \mathrm{~h}$, retirou-se uma alíquota de $25 \mathrm{~mL}$ do sobrenadante e, a seguir, foram adicionadas cinco gotas de fenolftaleína $10 \mathrm{~g} \mathrm{~L}^{-1}$. Determinou-se a quantidade de $\mathrm{H}+\mathrm{Al}$ por titulação $\mathrm{com} \mathrm{NaOH}$ 25 mmol (Silva, 1999).

Para a determinação do $\mathrm{pH}$ em água e $\mathrm{CaCl}_{2}$ $10 \mathrm{mmol} \mathrm{L}^{-1}$, foi utilizada à relação solo:solução de 1:2,5, efetuando-se a leitura na suspensão (Embrapa, 1997). Após a leitura do $\mathrm{pH}$ do solo, adicionaram-se 5,0; 10,0; 20,0 ou 40,0 mL da solução-tampão SMP em $\mathrm{pH} 7,5$, agitando por $15 \mathrm{~min}$ a $23 \mathrm{rad} \mathrm{s}^{-1}$. Após repouso por $60 \mathrm{~min}$, procedeu-se à leitura do $\mathrm{pH}$ de equilíbrio no sobrenadante (sem agitação) e na suspensão (com agitação) da solução SMP de equilíbrio. As análises de $\mathrm{pH} \mathrm{SMP}$ e de $\mathrm{H}+\mathrm{Al}$ em acetato de $\mathrm{Ca}$ foram efetuadas em três repetições.

$\mathrm{O}$ pH do solo antes da adição da solução SMP, o volume de solução-tampão SMP (relação solo:tampão SMP), leitura no sobrenadante e na suspensão da solução SMP de equilíbrio, e tipo de solo foram submetidos à análise de variância e teste de Scott \& Knott a $5 \%$ para verificar a influência na variável $\mathrm{pH}$ SMP.

Após esta análise de variância, utilizaram-se os valores médios para ajustar a equação de regressão, relacionando o $\mathrm{pH}$ SMP e a acidez potencial em acetato de Ca. As equações ajustadas foram comparadas pelo teste de identidade de modelo (TIM) para se verificar a hipótese de nulidade de que as equações são iguais estatisticamente. O teste de identidade de modelo baseia-se na diferença entre a soma dos quadrados de parâmetros do modelo completo e a soma de quadrados de parâmetros do modelo reduzido (Regazzi, 1996). Após o teste, a escolha da equação de melhor ajuste foi de acordo com o maior coeficiente de determinação $\left(\mathrm{R}^{2}\right)$ e coeficiente de correlação linear $(\mathrm{r})$ entre os dados de acidez potencial determinado pelo acetato de $\mathrm{Ca} \mathrm{e}$ estimado pelo $\mathrm{pH}$ SMP das equações ajustadas.

\section{RESULTADOS E DISCUSSÃO}

A determinação do pH SMP na suspensão ou no sobrenadante da solução de equilíbrio SMP não influenciou os valores de $\mathrm{pH} \operatorname{SMP}(\mathrm{p}>0,05)$ (Quadro 2) nos Organossolos estudados. Isto contribui para facilitar a rotina do laboratório de análise de solo, pois a determinação do pH SMP na suspensão é um procedimento de mais fácil execução pelo laboratorista do que a determinação no sobrenadante, com o cuidado de tocar ligeiramente o bulbo do eletrodo apenas na camada de terra sedimentada no fundo do frasco, conforme preconizado por Silva et al. (2006).

Os valores de pH SMP foram influenciados pela forma de determinar o $\mathrm{pH}$ do solo (água ou $\mathrm{CaCl}_{2}$ ) $(\mathrm{p}<0,01)$ pelo volume de solução-tampão SMP (relação solo:tampão SMP) adicionado $(\mathrm{p}<0,01)$ e pela interação entre esses fatores $(p<0,01)$ (Quadro 2). Observa-se que o valor do $\mathrm{pH}$ SMP aumentou em relação direta com o aumento do volume da soluçãotampão na suspensão solo:água ou $\mathrm{CaCl}_{2}$ :tampão SMP (Quadro 2). Valores superiores foram obtidos quando o pH SMP do solo foi determinado na suspensão solo:água em relação à suspensão solo: $\mathrm{CaCl}_{2}$, conforme encontrado por Ebeling (2006) em Organossolos de vários ambientes e estados brasileiros.

$\mathrm{O}$ aumento linear do $\mathrm{pH}$ SMP com aumento do volume de solução SMP ou diminuição da relação solo:tampão SMP ocorre porque, quando o solo é posto em contato com o tampão SMP, seus ácidos são neutralizados pelas bases do tampão, com conseqüente diminuição do $\mathrm{pH}$ da mistura (Galvão \& Vahl, 1996). Assim, à medida que se aumenta o volume da solução-tampão, maior quantidade de ácido do solo pode ser neutralizada até o possível esgotamento (Ebeling, 2006). Para Yuan (1974), o pH e o poder tampão do reagente são de importância fundamental na determinação da acidez potencial dos solos orgânicos.

Quadro 2. Valores de pH SMP em função da relação solo:solução-tampão SMP, forma de determinação do pH do solo (água ou $\mathrm{CaCl}_{2}$ ) e leitura do pH da solução SMP de equilíbrio (suspensão ou sobrenadante) em amostras de Organossolos da Serra do Espinhaço Meridional, Minas Gerais

\begin{tabular}{|c|c|c|c|c|c|c|}
\hline \multirow{3}{*}{$\begin{array}{c}\text { Relação } \\
\text { solo:tampão SMP }\end{array}$} & \multicolumn{4}{|c|}{ pH do solo } & & \\
\hline & \multicolumn{2}{|c|}{ pH água } & \multicolumn{2}{|c|}{$\mathrm{pH} \mathrm{CaCl}_{2}$} & \multicolumn{2}{|c|}{ Média (1) } \\
\hline & Suspensão & Sobrenadante & Suspensão & Sobrenadante & pH água & $\mathrm{pH} \mathrm{CaCl} \mathrm{Ca}_{2}$ \\
\hline $10: 5$ & 4,4 a C & 4,4 a C & 4,2 a D & 4,0 a D & 4,4 a C & $4,1 \mathrm{~b} \mathrm{D}$ \\
\hline $10: 10$ & 4,9 a $\mathrm{B}$ & 5,0 a $\mathrm{B}$ & 4,5 a C & 4,5 a C & 4,9 a $\mathrm{B}$ & $4,5 \mathrm{bC}$ \\
\hline $10: 20$ & 5,3 a B & 5,3 a B & 5,2 а B & 5,0 a B & 5,3 a $\mathrm{B}$ & $5,1 \mathrm{bB}$ \\
\hline $10: 40$ & 5,8 aA & 5,8 aA & 5,5 aA & 5,5 aA & 5,8 aA & $5,5 \mathrm{bA}$ \\
\hline
\end{tabular}

(1) Média dos valores de pH SMP com determinação na suspensão (com agitação) ou sobrenadante (sem agitação) da solução SMP de equilíbrio dentro de cada forma de determinação do $\mathrm{pH}$ do solo, correspondente a interação entre volume de solução-tampão SMP e pH do solo. Médias seguidas das mesmas letras minúsculas na linha dentro da forma de determinação do pH do solo e letras maiúsculas na coluna não diferem entre si pelo teste de Scott \& Knott a $5 \%$. 
Os valores de acidez potencial, determinados por titulação do extrato da solução de acetato de $\mathrm{Ca}$, variaram de 5,0 a $146,7 \mathrm{cmol}_{\mathrm{c}} \mathrm{dm}^{-3}$ de solo (Quadro 1), e foram superiores aos valores mencionados por Dolman \& Buol (1967). Conforme esses autores, o teor de $\mathrm{H}^{+}$nos solos orgânicos varia de 0 a $2,5 \mathrm{cmol}_{\mathrm{c}} \mathrm{dm}^{-3}$ em solos bem drenados, e de 2,0 a $12,0 \mathrm{cmol}_{\mathrm{c}} \mathrm{dm}^{-3}$ nos solos com má drenagem. A maior parte da acidez potencial dos Organossolos é decorrente do teor de $\mathrm{H}^{+}$provenientes de ácidos orgânicos do que do teor de $\mathrm{Al}^{3+}$ trocável (Adriesse, 1988; Lepsch et al., 1990), o que significa que a relação $\mathrm{Al} /(\mathrm{H}+\mathrm{Al})$ nestes solos pode ser ainda menor, conforme observado por Galvão \& Vahl (1996) em relação a solos minerais, nos quais a acidez está ligada à hidrólise do $\mathrm{Al}^{3+}$ trocável.

Foram ajustados modelos matemáticos que relacionam a acidez potencial determinada pelo acetato de Ca (Quadro 1) e os valores de $\mathrm{pH}$ SMP determinado na suspensão do tampão SMP de equilíbrio nas duas formas de determinação do $\mathrm{pH}$ do solo (água e $\mathrm{CaCl}_{2}$ ) e relações solo:tampão SMP para Organossolos da SdEM (Quadro 3). A equação exponencial foi a que melhor expressou a relação entre a acidez potencial $(\mathrm{H}+\mathrm{Al})$ e o pH SMP em cada situação (Quadro 3). Ajustes exponenciais também foram verificados para solos minerais, por Quaggio et al. (1985) para os solos do Estado de São Paulo, Sousa et al. (1989) para os solos de Cerrado; Maeda et al. (1997) para solo do Mato Grosso do Sul; Pereira et al. (1998) para solos do Rio de Janeiro; e Pavan et al. (1996) nos solos do Paraná; Escosteguy \& Bissani (1999) para solos do Rio Grande do Sul e Santa Catarina, e Silva et al. (2006) para solos do Vale do Jequitinhonha (MG), e Pereira et al. (2006) para Organossolos de vários estados do Brasil.

Para verificar a adequação dos modelos matemáticos entre acidez potencial e $\mathrm{pH}$ SMP dentro da forma de determinação de $\mathrm{pH}$ do solo (água ou $\mathrm{CaCl}_{2}$ ) com agitação da solução SMP de equilíbrio em cada relação solo:tampão SMP, foi realizado teste de identidade de modelos (TIM) de acordo com Regazzi (1996) (Quadro 3). Conforme pode ser verificado nesse quadro, as equações exponenciais ajustadas diferem entre si $(p<0,001)$ dentro da forma de determinação do $\mathrm{pH}$ do solo para cada relação solo:tampão SMP, confirmando a interação entre o $\mathrm{pH}$ do solo e a relação solo:tampão SMP nos valores de pH SMP (Quadro 2).

Conforme os resultados obtidos e em decorrência da elevada acidez dos Organossolos da SdEM e do seu elevado poder tampão, devido ao alto teor de C orgânico (Quadro 1), parece ser conveniente a utilização de $10 \mathrm{~mL}$ de solução-tampão SMP, em vez de $5 \mathrm{~mL}$, como é usado para solos minerais no método de análise de rotina, medido na suspensão solo:solução, associada à rotina de determinação do $\mathrm{pH}$ do solo em água ou $\mathrm{CaCl}_{2}$ (Quadro 3), pois foram os modelos exponenciais que apresentaram os maiores coeficientes de determinação $\left(\mathrm{R}^{2}\right)$ e correlação linear simples $(\mathrm{r})$ entre a acidez potencial determinada pelo acetato de $\mathrm{Ca}\left(\mathrm{H}+\mathrm{Al}_{\mathrm{AC}}\right) \mathrm{e}$ a estimada pelo modelo matemático (Quadro 3). A relação solo:tampão SMP de 10:10, para solos orgânicos do estado do Rio Grande do Sul e Santa Catarina, também foi verificada, por Galvão \& Vahl (1996), para

Quadro 3. Equações de regressão ajustadas, coeficientes de determinação $\left(R^{2}\right)$, correlação linear simples (r) e teste de identidade de modelos (TIM) entre acidez potencial determinado pelo acetato de cálcio $\left(\mathrm{H}+\mathrm{Al}_{\mathrm{AC}}\right)$ e pH SMP para quatro relações solo:tampão SMP com leitura do pH na suspensão da solução SMP de equilíbrio em amostras de Organossolos da Serra do Espinhaço Meridional, Minas Gerais.

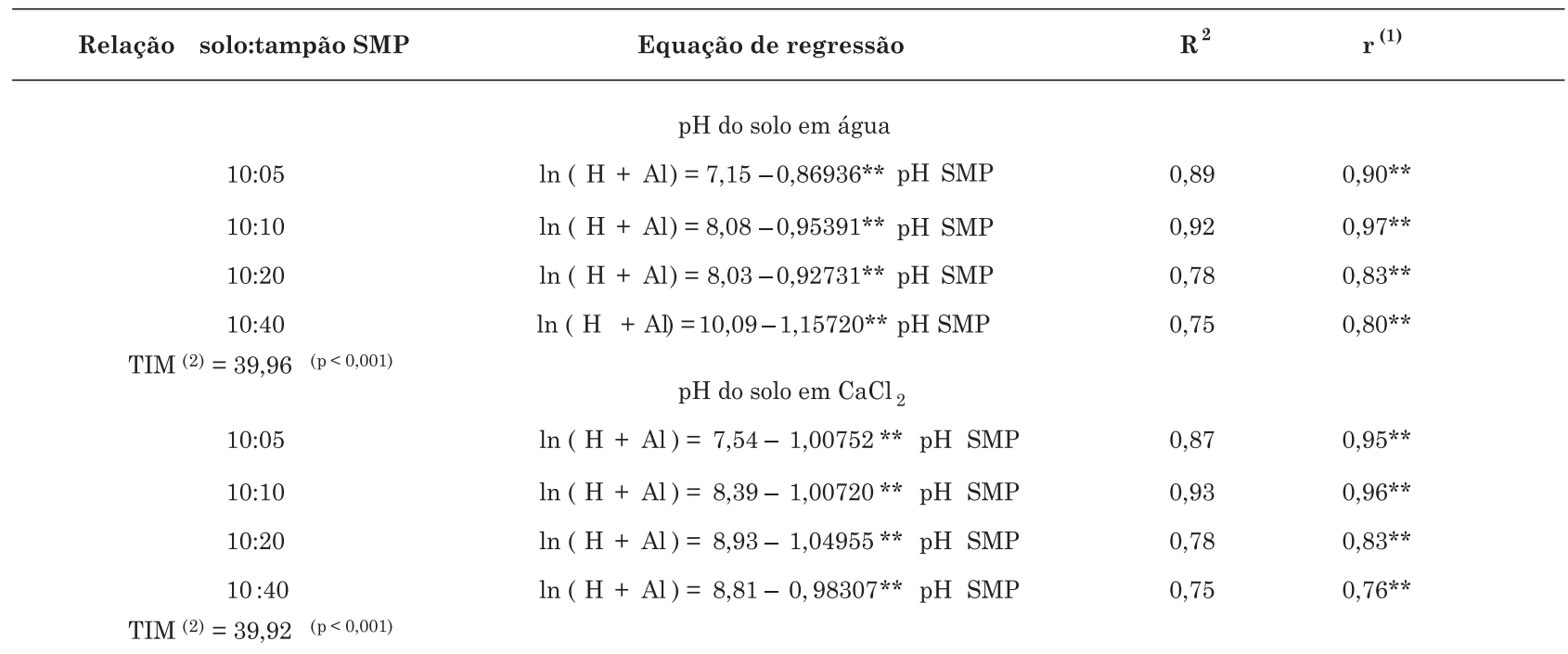

\footnotetext{
(1) Correlação linear simples entre $\mathrm{H}+\mathrm{Al}_{\mathrm{AC}}$ e $\mathrm{H}+\mathrm{A}$ estimado em cada equação de regressão. ${ }^{(2)}$ Teste de identidade de modelos que compara a diferença entre os modelos ajustados para cada relação solo:tampão SMP dentro de cada pH do solo, significativo a $0,1 \%$ pelo teste de F. ${ }^{* *}$ significativo a $1 \%$ pelo teste $\mathrm{t}$.
} 
recomendação de calagem pelo método SMP e sugerida por Quaggio et al. (1985) para solos com maior poder tampão do estado de São Paulo. Entretanto, de acordo com Dolman \& Buol (1967), a determinação do pH de solos orgânicos em suspensão solo-água é a que melhor reflete o seu $\mathrm{pH}$ do solo, talvez devido ao alto poder tampão desses solos (Galvão \& Vahl, 1996). Além disso, a determinação do $\mathrm{pH}$ SMP em água, na suspensão após o equilíbrio, deve-se ao fato de o método apresentar baixo custo e ser de fácil realização na rotina de determinação do $\mathrm{pH}$ em água, o que também foi discutido por Moreira et al. (2004) e Silva et al. (2006).

As diferenças observadas entre os modelos matemáticos obtidos neste trabalho e as anteriormente citadas, provavelmente devam-se aos elevados teores de C orgânico verificados nesses solos (Quadro 1). Segundo Escosteguy \& Bissani (1999), as variações constatadas entre as equações determinadas nas diversas regiões são decorrentes das variações na granulometria (teor e qualidade da argila), no teor e na qualidade da matéria orgânica e no pH, entre outros. Silva et al. (2002) e Silva et al. (2006), estudando a estimativa da acidez potencial pelo pH SMP em solos minerais das regiões norte e Vale do Jequitinhonha, ambas no Estado de Minas Gerais, verificaram que a aplicação de equações desenvolvidas para outras regiões do Brasil proporcionou uma superestimativa das quantidades de acidez potencial desses solos.

$\mathrm{O}$ atributo do solo que mais influiu na acidez potencial dos 22 Organossolos da SdEM foi o teor de C orgânico (CO), seguido pelo teor $\mathrm{Al}^{3+}$ trocável, conforme pode ser verificado pelos maiores valores de correlação positiva (Quadro 4). A correlação positiva do C orgânico com a acidez potencial foi encontrada também por Ebeling (2006) em solos com elevado teor de C orgânico de vários estados do Brasil. Isso se deve ao $\mathrm{H}^{+}$ associado às cargas negativas dependentes de $\mathrm{pH}$ dos

Quadro 4. Coeficientes de correlação linear simples (r) entre $\mathrm{pH}$ em água ou $\mathrm{CaCl}_{2}, \mathrm{Al}$ trocável $\left(\mathrm{Al}^{3+}\right)$, carbono orgânico (CO) e teor de argila e com a acidez potencial em acetato de cálcio para 22 amostras de Organossolos da Serra do Espinhaço Meridional, Minas Gerais

\begin{tabular}{lc}
\hline $\begin{array}{l}\text { Atributo do } \\
\text { Organossolo }\end{array}$ & $\begin{array}{c}\text { Coeficientes de } \\
\text { correlação linear simples (r) }\end{array}$ \\
\hline $\mathrm{pH}$ água & $-0,87^{* *}$ \\
$\mathrm{pH} \mathrm{CaCl}$ & $-0,86^{* *}$ \\
$\mathrm{Al}^{3+}\left(\mathrm{cmol}_{\mathrm{c}} \mathrm{dm}^{-3}\right)$ & $0,50^{*}$ \\
$\mathrm{CO}\left(\mathrm{g} \mathrm{kg}^{-1}\right)$ & $0,73^{* *}$ \\
$\mathrm{Argila}\left(\mathrm{g} \mathrm{kg}^{-1}\right)$ & $0,22^{\mathrm{ns}}$ \\
\hline $\mathrm{ns}, * \mathrm{e} * *$ não significativo, significativo a 5 e $1 \%$ pelo teste de \\
$\mathrm{t}$, respectivamente.
\end{tabular}

colóides orgânicos, à qual se dá por ligações covalentes, sendo, portanto, dissociável apenas com a elevação do pH pela solução SMP em pH 7,5 (Galvão \& Vahl, 1996). Para o $\mathrm{Al}^{3+}$ trocável, era esperada correlação positiva pelo fato da acidez potencial referir-se ao total de $\mathrm{H}^{+}$em ligação covalente, mais o $\mathrm{Al}^{3+}$, ou seja, a soma da acidez não-trocável e trocável (Silva et al., 2006). Da mesma forma, a correlação negativa com $\mathrm{pH}$ em água e $\mathrm{CaCl}_{2}$ do solo deve-se à relação inversa entre $\mathrm{pH}$ e $\mathrm{H}^{+}$ligado a colóides orgânicos devido aos elevados teores de C orgânico dos Organossolos estudados da SdEM (Quadro 1), tendência também encontrada por Ebeling (2006) para os solos orgânicos. A não-correlação significativa da acidez potencial com o teor de argila (Quadro 4) pode ser em virtude dos baixos teores de argila encontrados (Quadro 1) na maioria dos Organossolos estudados.

\section{CONCLUSÕES}

1. A acidez potencial dos Organossolos da SdEM pode ser estimada satisfatoriamente por meio da determinação do $\mathrm{pH}$ SMP na relação solo:tampão SMP de 10:10, medido na suspensão solo:solução SMP associado à rotina de determinação do $\mathrm{pH}$ do solo em água.

2. O teor de $\mathrm{C}$ orgânico foi o atributo químico que mais influenciou a acidez potencial dos Organossolos da SdEM.

\section{LITERATURA CITADA}

ADRIESSE, J. Nature and management of tropical peat soils. Roma, FAO, 1988. 165 p. (Bulletin Soils, 59).

BRASIL. Ministério do Planejamento e Orçamento. Fundação Instituto Brasileiro de Geografia e Estatística - IBGE. Diagnóstico ambiental da Bacia do Rio Jequitinhonha. Salvador, IBGE/Diretoria de Geociências, 1997.

DOLMAN, J.D. \& BUOL, S.W. A study of organic soils (Histosols): in the tidewater region of North Caroline. Raleigh, North Caroline Agricultural Experiment Station, 1967. 47p. (Technical Bulletin, 181)

EBELING, A.G. Caracterização analítica da acidez em organossolos. Rio de Janeiro, Universidade Federal Rural do Rio de Janeiro, 2006. 88p.

EMPRESA BRASILEIRA DE PASQUISA AGROPECUÁRIA EMBRAPA. Centro Nacional de Pesquisa de Solos. Manual de métodos de análise do solo. Brasília, 1997. 212p.

EMPRESA BRASILEIRA DE PASQUISA AGROPECUÁRIA EMBRAPA. Centro Nacional de Pesquisa de Solos Sistema brasileiro de classificação de solos. Brasília, 2006. $412 \mathrm{p}$. 
ESCOSTEGUY, P.A. \& BISSANI, C.A. Estimativa de $\mathrm{H}+\mathrm{Al}$ pelo $\mathrm{pH}$ SMP em solos do estado do Rio Grande de Sul e de Santa Catarina. R. Bras. Ci. Solo, 23:175-179, 1999.

FREITAS, L.M.M.; PRATT, P.F. \& VETTORI, L. Testes rápidos para estimar a necessidade de calcário em alguns solos do estado de São Paulo. Pesq. Agropec. Bras., 3:159-164, 1986.

GALVÃO, F.A.D. \& VAHL, L.C. Calibração do método SMP para solos orgânicos. R. Bras. Agroci., 2:121-130, 1996.

HORÁK, I.; SILVA, A.C.; FERREIRA, C.A.; RODRÍGUEZ RACEDO, J.; MARTÍNEZ CORTIZAS, A.; SILVA, E.B. \& GRAZZIOTTI, P.H. Turfeiras da Serra do Espinhaço Meridional - MG: I - Caracterização morfológica, física, química e microbiológica. In: CONGRESSO BRASILEIRO DE CIÊNCIA DO SOLO, 31., Gramado, 2007. Anais. Gramado, Sociedade Brasileira de Ciência do Solo, 2007. CD-ROM

LEPSCH, I.F.; QUAGGIO, J.A.; SAKAI, E.; CAMARGO, O.A. \& VALADARES, J.M.A.S. Caracterização, classificação e manejo agrícola de solos orgânicos do vale do Rio Ribeira de Iguape, SP. Campinas, Instituto Agronômico de Campinas, 1990. 58p. (Boletim Técnico, 131)

MAEDA, S.; KURIHRA, C.H.; HERNANI, L.C.; FABRICIO, A.C. \& SILVA, W.M. Estimativa da acidez potencial, pelo método do pH SMP, em solos do Mato Grosso do Sul. Dourados, Empresa Brasileira de Pesquisa Agropecuária, 1997. 25p. (Boletim de Pesquisa, 3).

MOREIRA, A.; ALMEIDA, M.P.; COSTA, D.G. \& SANTOS, L.S. Acidez potencial pelo método do $\mathrm{pH}$ SMP no Estado do Amazonas. Pesq. Agropec. Bras., 39:89-92, 2004.

NELSON, D.W. \& SOMMERS, L.E. Total carbon, organic carbon and organic matter. In: SPARKS, D.L.; PAGE, A.L.; HELMKE, P.A.; LOEPPERT, R.H.; SOLTANPOUR, P.N.; TABATABAI, M.A.; JOHNSTON, C.T. \& SUMMER, M.E., eds Methods of soil analysis. Part 3. Chemical methods. Madison, Soil Science Society of America and Americam Society of Agronomy, 1996. p.961-1009.. (Soil Science Society of America Book, Series, 5).

PAVAN, M.A.; OLIVEIRA, E.L. \& MIYAZAWA, M. Determinação indireta da acidez extraível do solo $(\mathrm{H}+\mathrm{Al})$ por potenciometria com a solução-tampão SMP. Arq. Biol. Tecnol., 39:307-312, 1996.

PEREIRA, M.G.; ANJOS, L.H.C. \& VALLADARES, G.S. Organossolos: ocorrência, gênese, classificação, alterações pelo uso agrícola e manejo. In: VIDAL-TORRADO, P.; ALLEONI, L.R.F.; COOPER, M.; SILVA, A.P.; CARDOSO, E.J. \& PROCHNOW, L.I., orgs. Tópicos em ciência do solo, Viçosa, MG, Sociedade Brasileira de Ciência do Solo, 2005. v.4. p.233-276.

PEREIRA, M.G.; BELING, A.G.; VALLADARES, G.S.; DOS ANJOS, L.H.C. \& ESPÍNDULA JR., A. Estimativa da acidez potencial pelo método do pH SMP em solos com elevado teor de matéria orgânica. Bragantia, 65:487-493, 2006.
PEREIRA, M.G.; VALLADARES, G.S.; SOUZA, J.M.P.F.; PÉREZ, D.V. \& DOS ANJOS, L.H.C. Estimativa da acidez potencial pelo método do $\mathrm{pH}$ SMP em solos do estado do Rio de Janeiro. R. Bras. Ci. Solo, 22:159-162, 1998.

QUAGGIO, J.A.; RAIJ, B.van \& MALAVOLTA, E. Alternative use of the SMP-buffer solution to determine lime requirement of soils. Comm. Soil Sci. Plant Anal., 16:245260,1985

RAIJ, B.van; CANTARELLA, H. \& ZULLO, M.A.T. O método tampão SMP para determinação da necessidade de calagem de solos do Estado de São Paulo. Bragantia, 38:5769, 1979.

REGAZZI, A.J. Teste para verificar a identidade de modelos de regressão. Pesq. Agropec. Bras., 31:1-17, 1996.

SAMBATTI, J.A.; SOUZA JUNIOR, I.G.; COSTA, A.C.S. \& TORMENA, C.A. Estimativa da acidez potencial pelo método do pH SMP em solos em formação Caiuá Noroeste do Estado do Paraná. R. Bras. Ci. Solo, 27:257264,2003

SILVA, A.C. Solos. In: SILVA, A.C.; PEDREIRA, L.C.V.S.F. \& ALMEIDA ABREU, P.A. Serra do Espinhaço Meridional: paisagens e ambientes. Belo Horizonte, O Lutador, 2005. p.61-77.

SILVA, A.C.; VIDAL TORRADO, P.; MARTINEZ-CORTIZAS, A. \& GARCIA-RODEJA, E. Soils of the São José Hills (Minas Gerais State, Brazil) and their relationship with palaeoclimate in southeastern Brazil. Braz. J. Soil Sci., 28:345-363, 2004

SILVA, C.A.; AVELLAR, M.L. \& BERNANDI, A.C.C. Estimativa da acidez potencial pelo $\mathrm{pH}$ SMP em solos do semi-árido do nordeste brasileiro. R. Bras. Ci. Solo, 24:689-692, 2000.

SILVA, E.B.; COSTA, H.A.O. \& FARNEZI, M.M.M. Acidez potencial estimada pelo método do $\mathrm{pH}$ SMP em solos da região do Vale do Jequitinhonha no estado de Minas Gerais. R. Bras. Ci. Solo, 30:751-757, 2006.

SILVA, E.B.; DIAS, M.S.C.; GONZAGA, E.I.C. \& SANTOS, N.M. Estimativa da acidez potencial pelo pH SMP em solos da região norte do estado de Minas Gerais. R. Bras. Ci. Solo, 26:561-565, 2002.

SILVA, F.C. Manual de análises químicas de solos, plantas e fertilizantes. Brasília, Empresa Brasileira de Pesquisa Agropecuária, 1999. 370p.

SOUSA, D.M.G.; MIRANDA, L.N.; LOBATO, E.; KLIEMAN, H.J. Avaliação de métodos para determinar as necessidades de calcário em solos do cerrado de Goiás e do Distrito Federal. R. Bras. Ci. Solo, 4:144-148, 1980.

SOUSA, D.M.G.; MIRANDA, L.N.; LOBATO, E. \& CASTRO, L.H.R. Métodos para determinar as necessidades de calagem em solos dos cerrados. R. Bras. Ci. Solo, 13:193198,1989

YUAN, T.L. A double buffer method for the determination of lime requeriment of acid soils. Soil Sci. Soc. Proc., 38:438440, 1974 